\title{
E2F7, regulated by miR-30c, inhibits apoptosis and promotes cell cycle of prostate cancer cells
}

\author{
YING WANG $^{1,2^{*}}$, XIAOJUAN PEI $^{3 *}$, PO XU $^{4 *}$, ZHIBO TAN $^{1}$, ZHENWEI ZHU $^{1}$, \\ GUANGPING ZHANG ${ }^{2}$, ZEYING JIANG ${ }^{1}$ and ZHE DENG ${ }^{4}$
}

\author{
${ }^{1}$ Oncology Department, Shenzhen Hospital, Southern Medical University, Shenzhen, Guangdong 518100; \\ ${ }^{2}$ Oncology Department, The First Affiliated Hospital of Henan University of Science and Technology, Luoyang, \\ Henan 471000; ${ }^{3}$ Pathology Department, Shenzhen Hospital, Southern Medical University, Shenzhen, Guangdong 518100; \\ ${ }^{4}$ Emergency Department, The First Affiliated Hospital, Shenzhen University, Shenzhen, Guangdong 518000, P.R. China
}

Received June 7, 2019; Accepted March 10, 2020

DOI: $10.3892 / o r .2020 .7659$

\begin{abstract}
Prostate cancer $(\mathrm{PCa})$ remains a leading cause of mortality among men in the United States and Western Europe. The molecular mechanism of PCa pathogenesis has not been fully elucidated. In the present study, the expression profile of E2F transcription factor 7 (E2F7) in PCa was examined using immunohistochemistry and reverse transcription-quantitative PCR, whilst cell cycle progression and apoptosis were determined using fluorescent cell activated sorting techniques. Cell viability was measured using Cell Counting Kit- 8 in loss- and gain-of-function studies. Dual-luciferase reporter assay was used to verify if E2F7 was one of the potential targets of miR-30c. The staining score of E2F7 of PCa tissues was found to be notably higher compared with that of adjacent normal tissues. Suppression of E2F7 expression in PCa cell lines led to significantly reduced proliferation rates, increased proportion of cells in the $\mathrm{G}_{1}$ phase of the cell cycle and higher apoptotic rates compared with those in negative control groups. Dual-luciferase reporter assay revealed E2F7 to be one of the binding targets of microRNA (miR)-30c. In addition, transfection of miR-30c mimics into PCa cells resulted in reduced cell viability, increased proportion of cells in the
\end{abstract}

Correspondence to: Dr Ying Wang, Oncology Department, Shenzhen Hospital, Southern Medical University, 1333 Xinhu Road, Shenzhen, Guangdong 518100, P.R. China

E-mail: wangying1333@smu.edu.cn

*Contributed equally

Abbreviations: PCa, Prostate cancer; E2F7, E2F transcription factor 7; IHC: immunohistochemistry; FACS, fluorescence-activated cell sorting; CCK-8, Cell Counting Kit-8; siRNA, small interfering RNA; RT-qPCR, reverse transcription-quantitative PCR; NC, negative control

Key words: prostate cancer, microRNA-30c, E2F transcription factor 7, cell cycle, apoptosis, proliferation
$\mathrm{G}_{1}$ phase and higher apoptotic rates. By contrast, transfection with the miR-30c inhibitor led to lower apoptosis rates of PCa cells compared with negative control groups, whilst E2F7 siRNA co-transfection reversed stimulatory effects of miR-30c inhibitors on cell viability. In addition, the expression of cyclin-dependent kinase inhibitor p21 were found to be upregulated by transfection with either E2F7 siRNA or miR-30c mimics into PCa cells. In conclusion, the present study suggested that E2F7 may be positively associated with PCa cell proliferation by inhibiting p21, whereas E2F7 is in turn under regulation by miR-30c. These observations suggest the $\mathrm{miR}-30 \mathrm{c} / \mathrm{E} 2 \mathrm{~F} 7 / \mathrm{p} 21$ axis to be a viable therapeutic target for $\mathrm{PCa}$.

\section{Introduction}

Lung, prostate and colorectal cancers are among the most frequent causes of mortality associated with cancer in men, accounting for $42 \%$ of all cases (1). In particular, prostate cancer (PCa) alone account for $20 \%$ of new diagnoses in the United States (1). Although factors associated with dietary, lifestyle and androgens have been recognized as contributors to increasing the risk of PCa (2), the molecular mechanisms of PCa tumorigenesis have not been fully elucidated.

The E2F family of transcription factors have been previously demonstrated to be important in the regulation of gene transcription involved in cell proliferation, differentiation and apoptosis in mamm alian cells $(3,4)$. The expression of a variety of E2F isoforms can be found in most cell types and have been characterized (3). It has been demonstrated that $\mathrm{E} 2 \mathrm{~F}$ serves a role in regulating the transcription profile associated with $\mathrm{G}_{1}-\mathrm{S}$ phase progression $(5,6)$. In addition, E2F7 has been previously revealed to suppress the transcription of a subset of E2F target genes, suggesting that E2F7 may function as a novel member of the mammalian E2F transcription factor family involved in the negative regulation of cellular proliferation (7). Recent studies implied that E2F7 functions as an oncogene in a multitude of malignant tumors, including cervical cancer (8) and liver cancer (9). E2F7 has been found to be overexpressed in primary blasts isolated from patients with acute myeloid leukemia (AML), where it 
promoted cell cycle progression and inhibited the monocytic differentiation of AML cells (10). A previous study suggested that miR-26a and E2F7 may form a double-negative feedback loop, resulting in the downregulation of miR-26a and upregulation of E2F7 in estrogen receptor-positive breast cancer, where Both miR-26a knockdown and E2F7 overexpression conferred resistance to tamoxifen in MCF-7 cells (11). In addition, E2F7 has also been demonstrated to be overexpressed in cutaneous squamous cell carcinoma compared with that in normal epidermis, where suppression of E2F7 expression in a squamous cell carcinoma cell line resulted in increased UV-induced and doxorubicin-induced apoptosis (12). It has been reported that inhibition of E2F7 nuclear export reinstated squamous cell carcinoma sensitivity to anthracyclines. Inhibition of E2F7 has also been similarly demonstrated to suppress Ishikawa and HEC-1B cell growth, suggesting that E2F7 is important for the tumorigenesis of endometrial carcinoma (13). In gallbladder cancer cells, E2F7 knockdown resulted in reduced tumor cell growth, whilst the upregulation of E2F7 resulted in the opposite effect (14). Additionally, E2F7 has been demonstrated to negatively regulate cyclin-dependent kinase (CDK) inhibitor p21 (p21CIP1/WAF1) transcription in HeLa cells (12), which is critical in promoting cell cycle arrest downstream of a variety of stimuli, including p53, transforming grwoth factor- $\beta$ and double homeobox 4 (15).

MicroRNAs (miRNAs) are a family of small non-coding RNA molecules 18-25 nucleotides in length that serve important functions across a variety of biological processes. Downregulation of miRNA expression in tumors compared with normal tissues has been frequently observed (16). miRNAs can bind to the 3'-untranslated region (3'-UTR) of target messenger RNAs (mRNAs) by complementary base pairing, which in turn interfere with the translation process or induce mRNA degradation $(17,18)$. It has been found that miR-30c may serve a tumor suppressor role in a number of tumor types by inhibiting physiological processes including cell migration, invasion and epithelial-to-mesenchymal transition (EMT) (19). Downregulation of miR-30c has been revealed to promote EMT in human renal cell carcinoma (20), whilst miR-30c can suppress PCa survival by negatively targeting the serine/arginine-rich splicing factor 1 (ASF/SF2) (21). In addition, it has been found that overexpression of miR-30c inhibited breast cancer cell growth (22).

In the present study, the role of miR-30c and E2F7 on PCa cell physiology was investigated by utilizing the transient transfection of the PCa cell lines DU145 and PC3. Dual-luciferase reporter assays were performed to verify if E2F7 is one of the potential targets of miR-30c. E2F7 was found to be overexpressed in PCa cells and tissues compared with that in their non-cancerous counterparts. In addition, inhibition of E2F7 and introduction of miR-30c into PCa cells led to significantly reduced cell proliferation. Dual-luciferase reporter assays demonstrated E2F7 to be one of the targets for miR-30c. Transfection with E2F7 siRNA or miR-30c mimics resulted in the upregulation of $\mathrm{p} 21$. These observations suggest that the dysregulation of E2F7 in PCa may contribute to PCa tumorigenesis, which may serve as a viable therapeutic target for PCa.

\section{Materials and methods}

Ethics. The procedures performed in this study were approved (approval no. YB M-05-01 V.2) by the Ethics Committee of the Shanghai Outdo Biotech Company, the member of National Human Genetic Resources Sharing Service Platform (Shanghai, China). The present study was performed in accordance with the ethical standards of The Institutional and National Research Committee (23) and with The Declaration of Helsinki. Written informed consent was acquired from all patients.

Tissue arrays. In this study, core tissue arrays (cat. no. HProA150CS01), including 50 paired samples of matched PCa samples and adjacent normal prostate samples and 50 additional PCa samples, were purchased from Shanghai Outdo Biotech Co., Ltd.

Cell lines and culture. The human PCa cell lines DU145, PC3 and the normal prostate epithelial cell line RWPE1 were kind gifts from Professor Xin Gao (Urology department, The Third Affiliated Hospital of Sun Yat-sen University, Guangzhou, China). PCa cells were cultured in RPMI-1640 medium (Hyclone; GE Healthcare Life Sciences) containing 10\% FBS (Hyclone; GE Healthcare Life Sciences) in a humidified sterile atmosphere containing $5 \% \mathrm{CO}_{2}$ at $37^{\circ} \mathrm{C}$.

Cell transfection. The human miR-30c mimics $(50 \mathrm{nM}$; cat. no. miR10000244-1-5; 5'-UGUAAACAUCCU ACACUCUCAGC-3'), the miR-30 inhibitor (100 nM; cat. no. miR20000244-1-5; 5'-GCUGAGAGUGUAGGAUGU UUACA-3') and the negative control (cat. no. miR01101-1-5; 5'-UUUGUACUACACAAAAGUACUG-3') were synthesized by Guangzhou RiboBio Co., Ltd. For E2F7 knockdown, siRNAs were used (50 nM; cat. no. sc-44590; sense, 5'-GUA AACCAGCCUUCAAGUGdTdT-3' and anti-sense, 5'-dTdTCA UUUGGUCGGAAGUUCAC-3'; Santa Cruz Biotechnology, Inc.). Cells were transfected using Lipofectamine ${ }^{\circledR} 2000$ transfection reagent (Invitrogen; Thermo Fisher Scientific, Inc.) according to manufacturer's protocols. Cells were harvested $48 \mathrm{~h}$ after transfection for Cell Counting Kit-8 (CCK-8), cell cycle, apoptosis and western blotting analyses.

Reverse transcription-quantitative PCR (RT-qPCR). Total RNA was extracted from the PCa and normal prostate cell lines using the TRIzol ${ }^{\circledR}$ reagent (Invitrogen; Thermo Fisher Scientific, Inc.) and examined on a NanoDrop machine according to the manufacturer's protocols (Eppendorf). Electrophoresis and spectrophotometric methods were used to examine the concentrations and purity of the RNA samples. cDNA was prepared using ImProm-II ${ }^{\mathrm{TM}}$ Reverse Transcription System according to manufacturer's protocols (cat. no. A3800; Promega Corporation). The temperature protocol of reverse transcription reactions was as follows: i) mRNA, $85^{\circ} \mathrm{C}$ for $5 \mathrm{~min}, 30^{\circ} \mathrm{C}$ for $10 \mathrm{~min}, 42^{\circ} \mathrm{C}$ for $60 \mathrm{~min}$ and $85^{\circ} \mathrm{C}$ for $10 \mathrm{~min}$; and ii) $85^{\circ} \mathrm{C}$ for $5 \mathrm{~min}, 42^{\circ} \mathrm{C}$ for $60 \mathrm{~min}$ and $85^{\circ} \mathrm{C} 10 \mathrm{~min}$ for miRNA. Platinum ${ }^{\mathrm{TM}}$ SYBR $^{\mathrm{TM}}$ Green qPCR SuperMix-UDG (cat. no. 11733046, Invitrogen; Themo Fisher Scientific, Inc.) was used for qPCR and each reaction was performed in triplicate. The thermocycling conditions used for RT-qPCR were 
as follows: Activation at $50^{\circ} \mathrm{C}$ for $2 \mathrm{~min}$, Initial denaturation at $95^{\circ} \mathrm{C}$ for $2 \mathrm{~min}$, followed by 40 cycles of $95^{\circ} \mathrm{C}$ for $15 \mathrm{sec}$ and $60^{\circ} \mathrm{C}$ for $32 \mathrm{sec}$. The $2^{-\Delta \Delta \mathrm{Cq}}$ method (24) was utilized to calculate the relative expression levels of mRNA and miRNA (primers used can be seen in Table SI), using GAPDH and U6 as reference genes for mRNA and miRNA, respectively.

Western blotting. Western blotting was performed as previously described $(25,26)$. DU145 and PC3 cells were lysed in RIPA Buffer (Beyotime Institute of Biotechnology) containing protease inhibitors on ice followed by centrifugation at $1,000 \mathrm{x}$ g for $15 \mathrm{~min}$ at $4^{\circ} \mathrm{C}$. The protein concentration was quantified using bicinchoninic acid Protein Assay Kit (Beyotime Institute of Biotechnology), following which the protein samples $(30 \mu \mathrm{g})$ were separated using $12 \%$ SDS polyacrylamide gels and transferred onto PVDF membranes (EMD Millipore). Membranes were blocked with 5\% non-fat milk powder at room temperature for $1 \mathrm{~h}$ and incubated overnight at $4^{\circ} \mathrm{C}$ with primary antibodies. Anti-E2F7 primary antibody (1:200; cat. no. ab56022) was obtained from Abcam, Anti-p21 primary antibody (1:200; cat. no. 10355-1-AP) was obtained from Proteintech Group, Inc., whilst the anti-GAPDH primary antibody (1:600; cat. no. 10494-1-AP) was purchased from ProteinTech Group, Inc. Membranes were incubated with horseradish peroxidase-conjugated secondary antibodies (1:2,000; cat. no. SA00001-2; ProteinTech Group, Inc.) for $1 \mathrm{~h}$ at room temperature after three $10 \mathrm{~min}$ washes in TBS supplemented with $0.1 \%$ Tween-20. Finally, immunodetection and visualization of the membranes were performed using the ECL kit (Pierce; Thermo Fisher Scientific, Inc.) which were subsequently scanned and using a Bio-Rad ChemiDoc XRS+ imaging system (Bio-Rad Laboratories, Inc.) and analyzed using the Image J software (version 1.8.0; National Institutes of Health). The protein expression was normalized to an endogenous reference (GAPDH) and relative to the control.

miRNA target prediction. To predict potential miRNA target genes, the microRNA.org website (2010 version; http://www. microrna.org/microrna/home.do) and TargetScan Human 5.1 (http://www.targetscan.org/vert_72/) were used by entering 'E2F7' into the search box to see if there are binding sites for miR-30c. Free binding energy was calculated and binding sites were analyzed using the BiBiServ website (http://bibiserv. techfak.uni-bielefeld.de/rnahybrid).

Construction of luciferase reporter plasmids, transfection and dual-luciferase assay. In the present study, the plasmid containing the 3'-UTR of E2F7 was constructed using the psiCHECK-2 dual luciferase vector (cat. no. C8011; Promega Corporation). The fragments containing the predicted wild-type (wt) and mutant (mut) sites of E2F7 3'UTR were first directly synthesized by Guangzhou RiboBio Co., Ltd., followed by subcloning into the psiCHECK-2 vector at the XhoI and NotI restriction sites to generate the E2F7-3'-UTRwild-type and E2F7-3'-UTR-mutant vectors. The following primer pairs were used to generate the E2F7-3'UTR mut plasmid: Forward, 5'-TTTATCAACACTAAACTTTTAAAA CCCGTGAGTTTTTTTTTTCTTTTTTACAGTCTTC-3' and reverse, 5'-GAAGACTGTAAAAAAGAAAAAAAAAAC TCACGGGTTTTAAAAGTTTAGTGTTGATAAA-3'. The following primer pairs were used to generate the E2F7-3'UTR wt plasmid: Forward, 5-'CCGCTCGAGCCTGCCGCTTTG CCAGGTGGG-3' and reverse, 5'-ATAAGAATGCGGCCGC TTCTTCTTAAATGAATTATTTTTTATTG-3'.

Du145 and PC3 cells (1x105/well) were seeded into a 24-well plates and co-transfected with E2F7-3'-UTR-wild or E2F7-3'-UTR-mutant vectors (50 ng/well) and miR-30c mimic (50 nM/well). Lipofectamine ${ }^{\circledR} 2000$ (Invitrogen; Thermo Fisher Scientific, Inc.) was used for transfection. NC mimics (50 nM/well; 5'-UUUGUACUACACAAAAGUACUG-3') and NC inhibitor (100 nM/well; 5'-CAGUACUUUUGUGUA GUACAAA-3') were used as control. Cells were collected $48 \mathrm{~h}$ later and luciferase activities were measured using the Dual-Luciferase ${ }^{\circledR}$ Reporter Assay kit according to manufacturer's protocols (Promega Corporation) on a GloMax ${ }^{\circledR} 96$ Microplate Luminometer (Promega Corporation). All results were normalized to those of Renilla luciferase activities to verify the luciferase activities.

Cell viability assay. Cell Counting kit-8 (CCK-8; Nanjing KeyGen Biotech Co., Ltd.) was used according to the manufacturer's protocols to examine cell viability. Du145 and PC 3 cells were seeded onto 96 -well plates $\left(1 \times 10^{4}\right.$ cells/well $)$, following which cell viability was measured every $24 \mathrm{~h}$ for 5 days. The number of the viable cells was evaluated by assessment of absorbance values at $450 \mathrm{~nm}$ using a Multiskan MK3 microplate reader (Thermo Fisher Scientific, Inc.).

Cell cycle analysis. PC3 and DU145 were cultured using the RPMI-1640 medium (Invitrogen; Thermo Fisher Scientific) supplemented with $10 \%$ FBS in 6-well plates for $48 \mathrm{~h}$ before being collected. Transfection was performed when cells reached $80-90 \%$ confluency. A total of $1 \times 10^{4}$ cells cells were then collected $48 \mathrm{~h}$ after transfection, washed twice using PBS and fixed in $70 \%$ ethanol at $4^{\circ} \mathrm{C}$ overnight, followed by incubation with $5 \mu \mathrm{l}$ propidium iodide $(50 \mu \mathrm{g} / \mathrm{ml}$; cat. no. KGA511; Nanjing KeyGen Biotech Co., Ltd) for each sample at room temperature for $1 \mathrm{~h}$. Finally, the cells were analyzed using flow cytometry (BD FACScalibur ${ }^{\mathrm{TM}}$; BD Biosciences) using the ModFitLT ${ }^{\mathrm{TM}}$ software (version 3.0; Verity Software House, Inc.).

Apoptosis assay. Transfection was performed when DU145 and PC3 cells reached 80-90\% confluency for $48 \mathrm{~h}$, followed by cell collection for apoptosis analysis. The degree of cell apoptosis was measured using the Annexin V-FITC/PI apoptosis detection kit (cat. no. KGA106; Nanjing KeyGen Biotech Co., Ltd.) according to the manufacturer's protocols. A total of $1 \times 10^{4}$ cells were used per staining reaction. Cell apoptosis rates were assessed using flow cytometry (BD FACScalibur ${ }^{\mathrm{TM}}$; BD Biosciences) using the ModFitLT ${ }^{\mathrm{TM}}$ software (version 3.0; Verity Software House, Inc.).

5-Ethynyl-2'-deoxyuridine (EdU) assay. DU145 and PC3 cells $\left(5 \times 10^{5}\right.$ cells/cell) were seeded into six-well plates at $37^{\circ} \mathrm{C}$ $24 \mathrm{~h}$ before transfection was performed and were incubated overnight to reach $30-50 \%$ confluence. Transfection was then performed for $48 \mathrm{~h}$. EdU solution (Guangzhou RiboBio Co., Ltd.) was subsequently diluted using RPMI-1640 medium at a ratio of $1: 1,000$ to prepare a $50 \mu \mathrm{M}$ EdU solution. When $80-90 \%$ confluency was reached, each well was treated with 
A

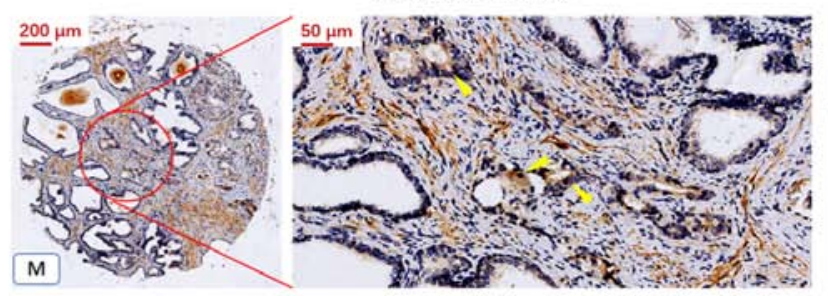

Prostate cancer

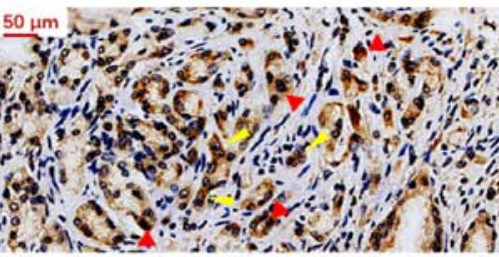

Paracancerous
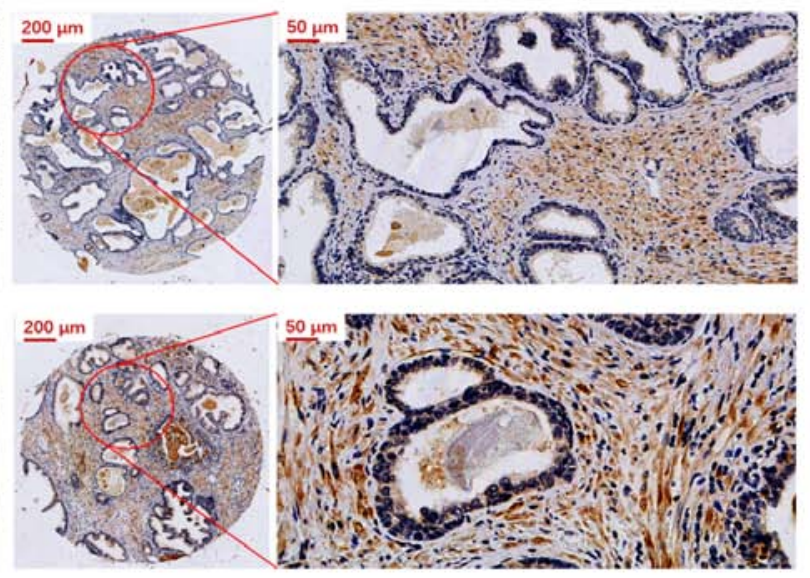

B

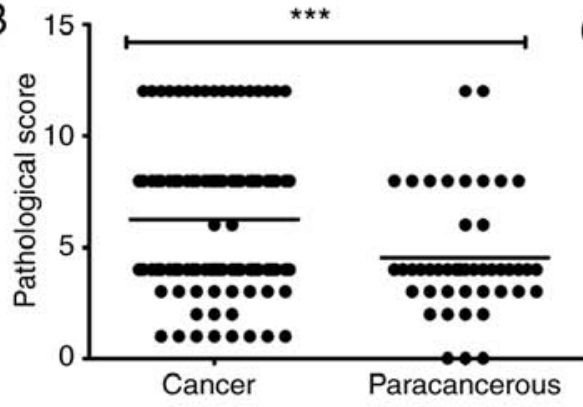

E
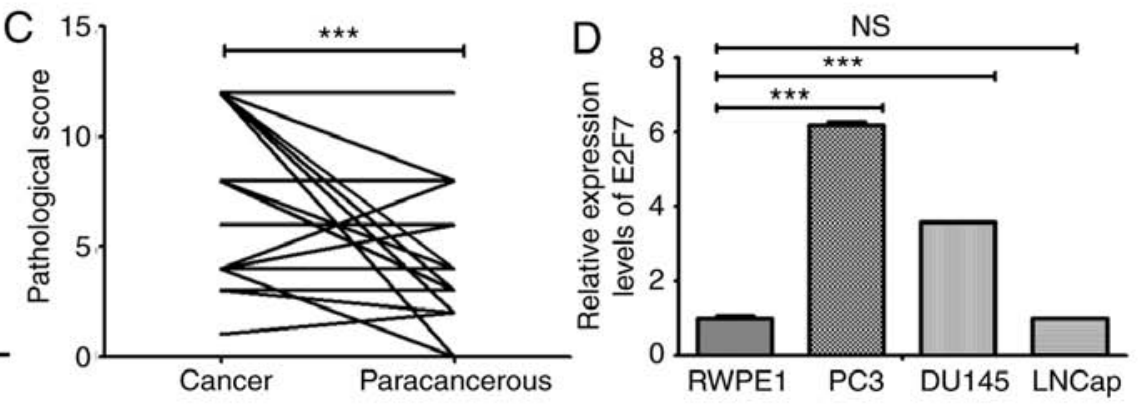

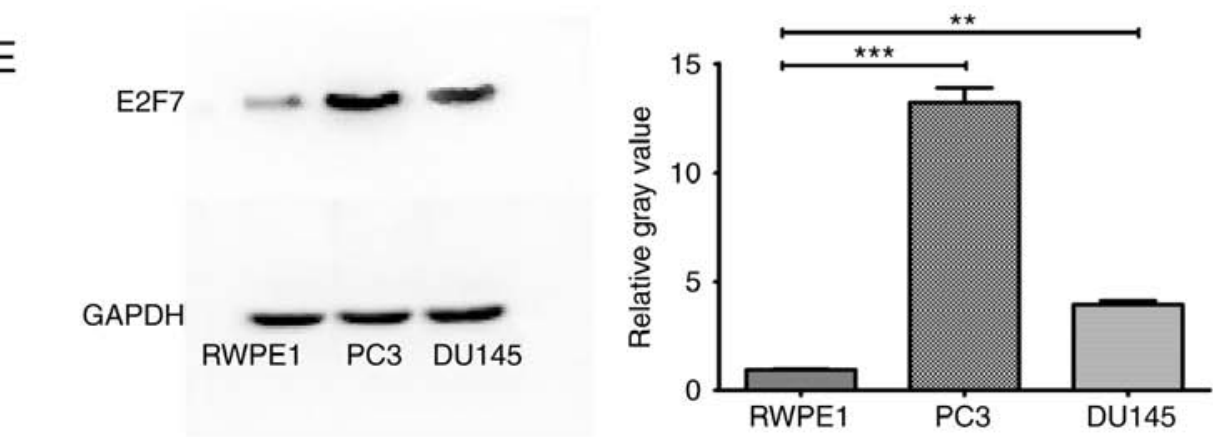

Figure 1. Comparison of E2F7 expression levels between prostate cancer and normal prostate tissues and cell lines. (A) Representative immunohistochemical staining images of E2F7 in prostate cancer and adjacent normal tissues microarrays. Red arrows, nuclei staining; yellow arrows, cytoplasm staining. M: moderately differentiated; P: poorly differentiated. (B) Staining scores of E2F7 expression in PCa ( $\mathrm{n}=93$ ) and adjacent normal prostate tissue arrays ( $\mathrm{n}=45$ ). ${ }^{* * *} \mathrm{P}<0.0001$. (C) Staining scores of E2F7 expression in paired prostate cancer $(\mathrm{n}=45)$ and matched adjacent non-cancerous tissues $(\mathrm{n}=45)$. ${ }^{* * *} \mathrm{P}<0.0001$. (D) Comparison of E2F7 mRNA expression in prostate cancer cell lines DU145 and PC3 cells and in the normal prostate cell line RWPE1 cells. ${ }^{* * *} \mathrm{P}<0.0001$. (E) Comparison of E2F7 protein expression in prostate cancer cell lines DU145 and PC3 cells, and in the normal prostate cell line RWPE1. * P $<0.01$ and ${ }^{* * *} \mathrm{P}<0.0001$. The values represent the mean \pm SD from three experimental repeats. $\mathrm{M}$, moderately differentiated; $\mathrm{P}, \mathrm{poorly}$ differentiated; NS, not significant.

$100 \mu 150 \mu \mathrm{M}$ EdU solution for $2 \mathrm{~h}$ at room temperature, following which $4 \%$ paraformaldehyde was added to each well and the cells were incubated for 15-30 min at room temperature. The cells were then incubated with $2 \mathrm{mg} / \mathrm{ml}$ glycine for 2 min, then $100 \mu$ l detergent $(0.5 \%$ Triton X-100 in PBS) was used to permeabilize cells in each well at room temperature for $5 \mathrm{~min}$. A total of $100 \mu \mathrm{l} 1 \mathrm{X}$ Apollo ${ }^{\circledR} 567$ staining solution (cat. no. C10316-1; Guangzhou RiboBio Co., Ltd.) was added to each well, where the cells were then protected from light and incubated for $30 \mathrm{~min}$ at room temperature. Finally, $100 \mu \mathrm{l}$ 1X Hoechst 33342 reaction solution (Guangzhou RiboBio Co., Ltd.) was added to each well in the dark for 10-30 min followed by observation and analysis using a fluorescent inverted microscope (Magnification, x100; DMI6000B; Leica
Microsystems $\mathrm{GmbH}$. Images were analyzed using the Image J software (version 1.44p; National Institutes of Health).

Immunohistochemical (IHC) staining. All sections were first deparaffinized by washing in xylene I for $15 \mathrm{~min}$, xylene II for $15 \mathrm{~min}$ and xylene III for $15 \mathrm{~min}$, followed by rehydration using a descending ethanol gradient. Antigen retrieval was then performed, where the tissue microarrays were incubated in EDTA antigen repair buffer solution (pH 8.0; cat. no. G1206; Wuhan Servicebio Technology Co., Ltd.) at $95^{\circ} \mathrm{C}$ for $10 \mathrm{~min}$. Tissue sections were permeabilized by incubation with Triton $\mathrm{X}-100$ solution at room temperature for $10 \mathrm{~min}$. The slides were then washed with PBS ( $\mathrm{pH}$ 7.4) for three times at $5 \mathrm{~min}$ each, following which they were treated with $3 \%$ endogenous 
peroxidase blocking buffer (cat.no.P0100A; Beyotime Institute of Biotechnology) at room temperature in the dark for $25 \mathrm{~min}$ block endogenous peroxidase activities. After another round of washing using PBS for three times at 5 min each, the sections were blocked with 3\% BSA (Wuhan Servicebio Technology Co., Ltd.) at room temperature for $30 \mathrm{~min}$. IHC staining of tissue microarrays was performed by incubation with the anti-E2F7 (1:200; cat. no. ab56022; Abcam) and anti-p21 (1:200; cat. no. 10355-1-AP; Proteintech Group, Inc.) primary antibodies overnight at $4{ }^{\circ} \mathrm{C}$. The tissue microarrays were then incubated with HRP-conjugated secondary antibodies (1:500; cat. no. G23303; Wuhan Servicebio Technology Co., Ltd.) at room temperature for $1 \mathrm{~h}$ after washing three times with PBS. Finally, the microarrays were immersed in 3,3'-diaminobenzidine for 5-10 min at room temperature and counterstained with $10 \%$ Mayer's hematoxylin at room temperature for $3 \mathrm{~min}$. Images of the microarrays were obtained using a digital scanner (Pannoramic MIDI; 3DHISTECH, Ltd.). An independent pathologist (XJP) blinded to the clinical data scored the samples. The stained slides were graded according to the estimated proportion of cells whose nuclei stained positive: i) $0,0 \%$ of cells; ii) $1,1-25 \%$; iii) $2,26-50 \%$; iv) $3,51-75 \%$; and iv) 4, 76-100\%. In addition, the staining intensity was also graded as follows: i) 0 , none; ii) 1 , weak; iii) 2 , intermediate; and iv) 3, strong. Total score='staining intensity score' $\mathrm{x}$ 'staining positive rate score' $(27,28)$.

Statistical analysis. Data were presented as the mean \pm SD from three experimental repeats. The SPSS statistical software (version 17.0; SPSS, Inc.) was used to perform statistical analyses. Wilcoxon signed-rank test was used to compare the immunohistochemistry scores of unpaired and paired cancer and matched adjacent non-cancerous tissues, separately. Comparison between multiple groups was performed using one-way ANOVA followed by Tukey's post hoc test. $\mathrm{P}<0.05$ were considered to indicate a statistically significant difference.

\section{Results}

Upregulation of E2F7 expression in PCa tissues and cell lines. To assess the expression levels of E2F7 in PCa, E2F7 expression of $93 \mathrm{PCa}$ tissues and 45 adjacent non-cancerous prostate tissues were examined using IHC. It was found that E2F7 was mainly expressed in the nuclei of the poorly differentiated PCa tissues, whilst it was mainly expressed in the cytoplasm of highly or moderately differentiated PCa tissues (Figs. 1A and S1). The staining scores of E2F7 of PCa tissues were found to be markedly higher compared with those of adjacent normal tissues (Fig. 1B). The further comparison revealed that the staining scores in $\mathrm{PCa}$ tissues was significantly higher compared with their corresponding paired matched adjacent non-cancerous tissues (Fig. 1C). E2F7 expression was subsequently evaluated in three different $\mathrm{PCa}$ cell lines. The mRNA expression levels of E2F7 in PCa cell lines DU145 and PC3 were found to be significantly higher compared with those in the normal prostate cell line RWPE1 (Fig. 1D). Western blotting also showed that the levels of E2F7 expression in PC3 and DU145 cells were significantly higher compared with those of the RWPE1 cells (Fig. 1E).
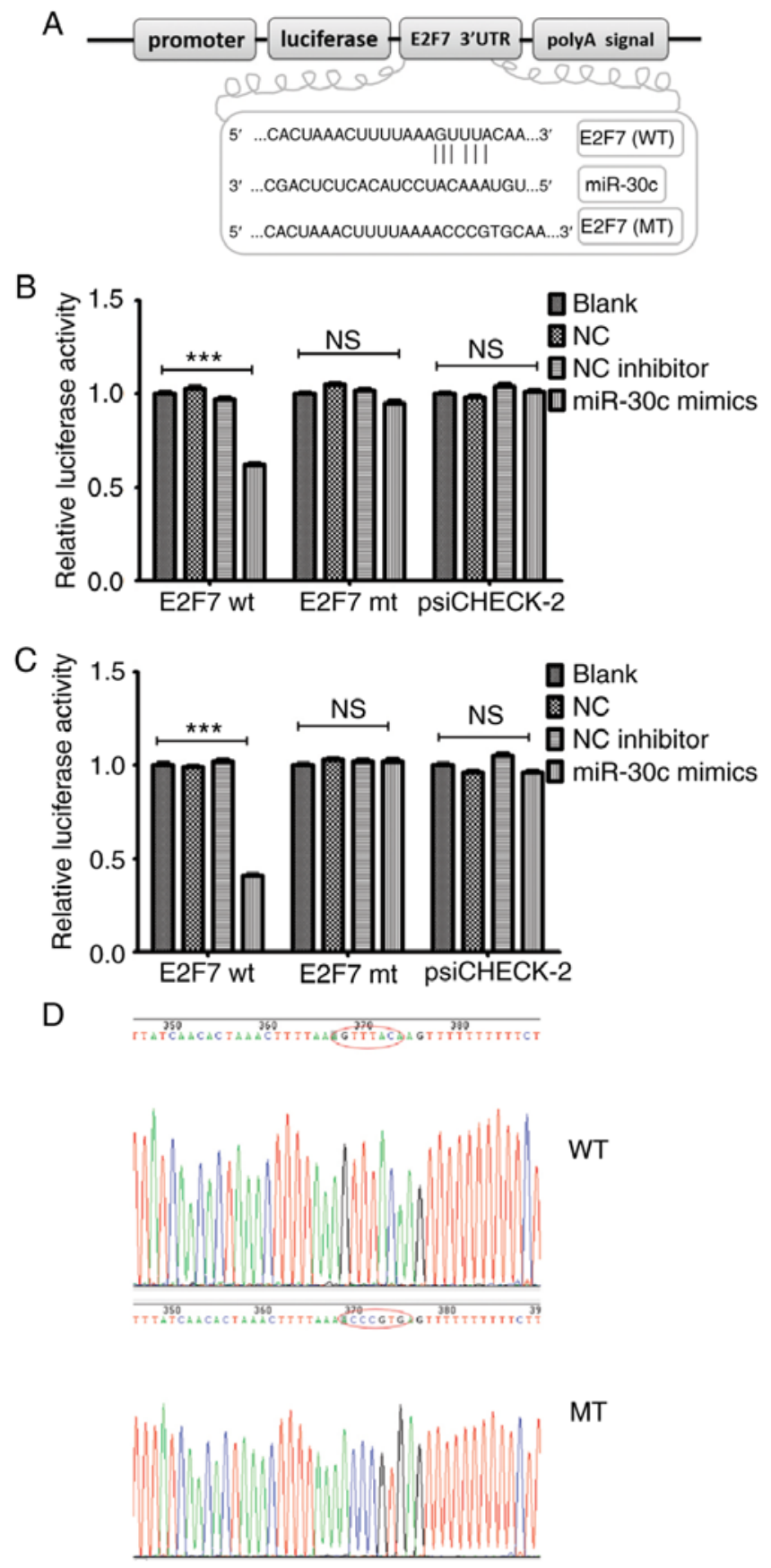

Figure 2. Verification of the potential predicted interaction between E2F7 and miR-30c. (A) The schematic diagram of the construction of the psiCHECK-2 vector encoding E2F7 3'UTR and E2F7 3'Mut UTR. Both LucE2F7 3'UTR and Luc- E2F7 3'mutant UTR were cloned into a psiCHECK-2 plasmid downstream of the firefly luciferase coding region between the XhoI and NotI sites. (B) DU145 cells and (C) PC3 cells were co-transfected with psiCHECK-2 constructs encoding either E2F7 wild-type 3'UTR or E2F7 mutant 3'UTR and either the miR-30c mimics for $48 \mathrm{~h}$, following which their respective luciferase activities were measured. (D) Sequencing data of wild-type E2F7 3'UTR and mutant E2F7 3'UTR. The values represent the mean \pm SD from three experimental repeats. ${ }^{* * *} \mathrm{P}<0.0001$. miR, microRNA; 3'UTR, 3'untranslated region; NS, not significant; MUT or mt, mutant; WT, wild-type; $\mathrm{NC}$, negative control.

E2F7 is a functional target of miR-30c. The aforementioned observations suggested that E2F7 may function as an oncogene in PCa. Therefore, potential downstream targets of miR-30c were searched using online tools TargetScan Human 5.1 

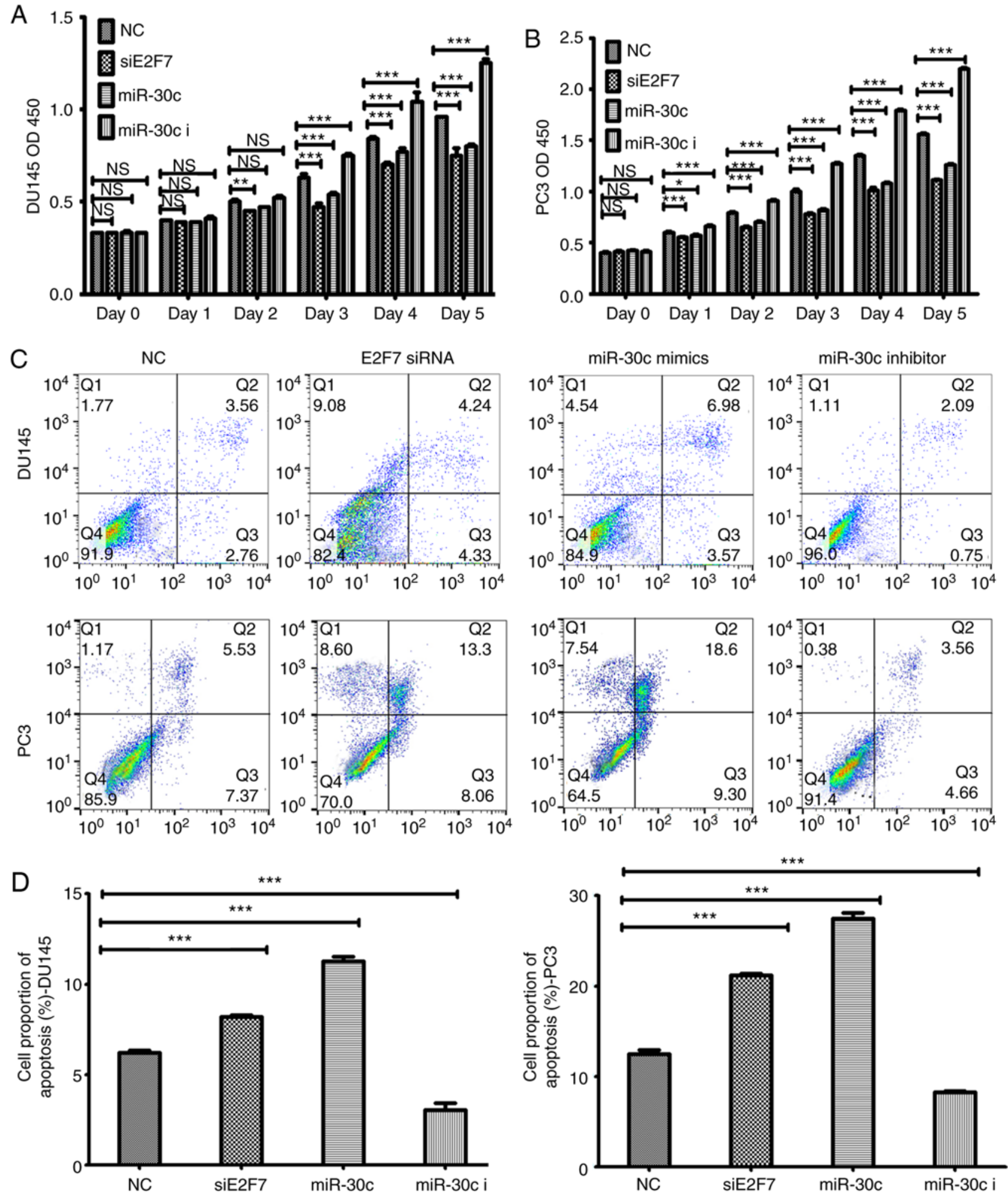

Figure 3. Effects of E2F7 knockdown, miR-30c overexpression and miR-30c inhibition on prostate cancer cell viability and apoptosis. CCK-8 assay results of (A) DU145 and (B) PC3 cells, where cell viability was measured every $24 \mathrm{~h}$ over 5 days following their respective transfections. (C) Representative flow cytometry dot plots showing that transfection with the miR-30c mimics or E2F7 siRNA increased the apoptotic rates of DU145 and PC3 cells compared with the those transfected with NC, whilst transfection with the miR-30c inhibitor resulted in the opposite effect. (D) Quantified data using cell counts from the Q2 and $\mathrm{Q} 3$ quadrants $(\mathrm{C})$. The values represent the mean $\pm \mathrm{SD}$ from three experimental repeats. ${ }^{*} \mathrm{P}<0.05,{ }^{* *} \mathrm{P}<0.01$ and ${ }^{* * *} \mathrm{P}<0.0001$. miR, microRNA; siRNA, small interfering RNA; miR-30c, miR-30c mimics; miR-30c I, miR-30c inhibitor; siE2F7, E2F7 siRNA; OD, optical density; NS, not significant.

(Conserved) (http://www.targetscan.org/vert_72/) and microRNA.org (http://www.microrna.org/microrna/home.do). E2F7 was found to be one of the potential targets of miR-30c in $\mathrm{PCa}$, as it predicted to have putative miR-30c binding sites within its 3'-UTR (Fig. 2A). Luciferase reporter assays were subsequently performed to verify whether E2F7 is a direct target of miR-30c using DU145 and PC3 cell lines. DU145 and PC 3 cell lines were co-transfected with a psiCHECK-2 

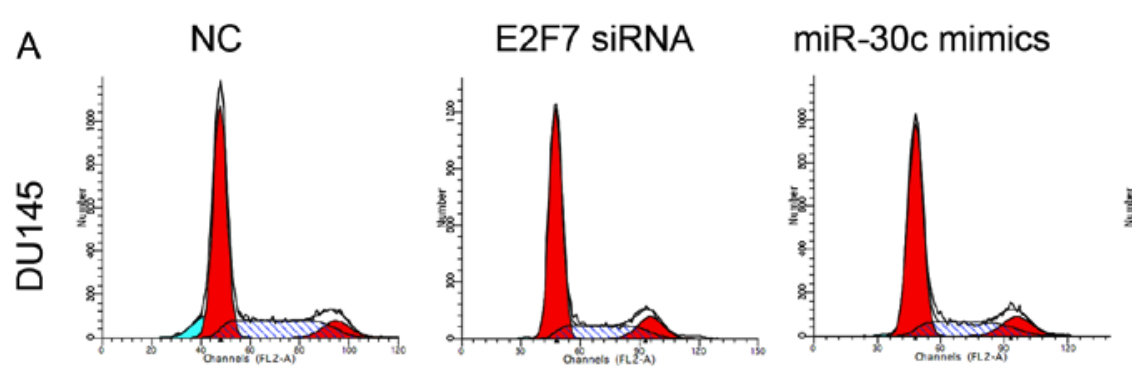

miR-30c inhibitor
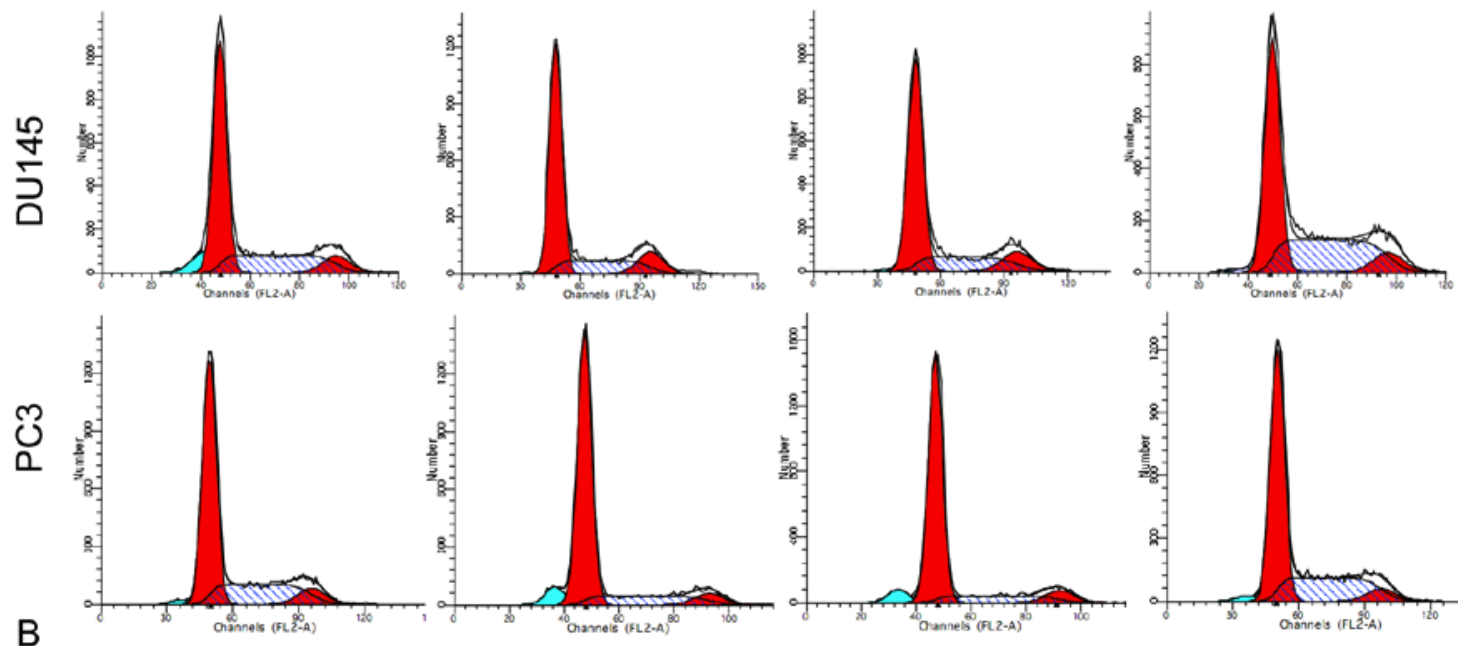

B
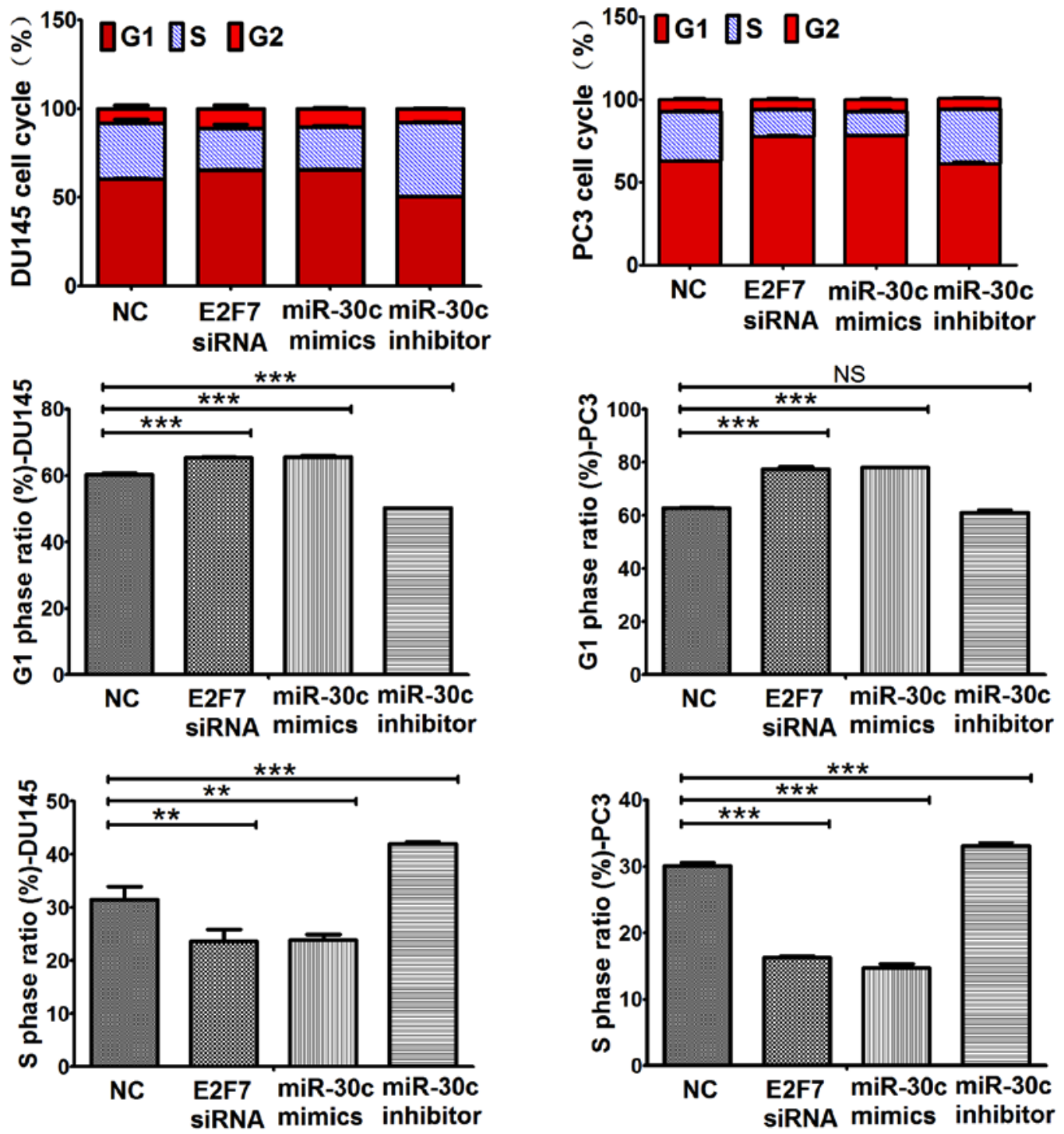

Figure 4. Effects of E2F7 knockdown, miR-30c overexpression and miR-30c knockdown on prostate cancer cell cycle progression. (A) Representative histograms showing the proportion of Du145 and PC3 cells in the $\mathrm{G}_{1}, \mathrm{~S}$ and $\mathrm{G}_{2}$ phases of the cell cycle following transfection with either NC, miR-30c mimics, E2F7 siRNA or miR-30c inhibitors. Dark red indicates cells in $\mathrm{G}_{1}$ phase; Light red indicates cells in $\mathrm{G}_{2}$ phase; Teal indicates apoptotic cells; Blue indicates cells in S phase. (B) Transfection with the miR-30c mimic and E2F7-siRNA increased the percentage of DU145 and PC3 cells in the $\mathrm{G}_{1}$ phase of the cell cycle whilst transfection with the miR-30c inhibitor resulted in the opposite effect. No significant difference was observed in the $\mathrm{G}_{1}$ phase ratio between miR-30c inhibitor transfection group and the NC group in PC3 cells. Transfection with miR-30c mimics and E2F7-siRNA reduced the percentage of DU145 and PC3 cells in the S phase of the cell cycle whilst transfection with the miR-30c inhibitor resulted in the opposite effect. The values represent the mean \pm SD from three experimental repeats. ${ }^{* *} \mathrm{P}<0.01$ and ${ }^{* * * *} \mathrm{P}<0.0001$, NS, not significant. miR, microRNA; miR-30c, miR-30c mimics; miR-30c I, miR-30c inhibitor; NC, negative control. 

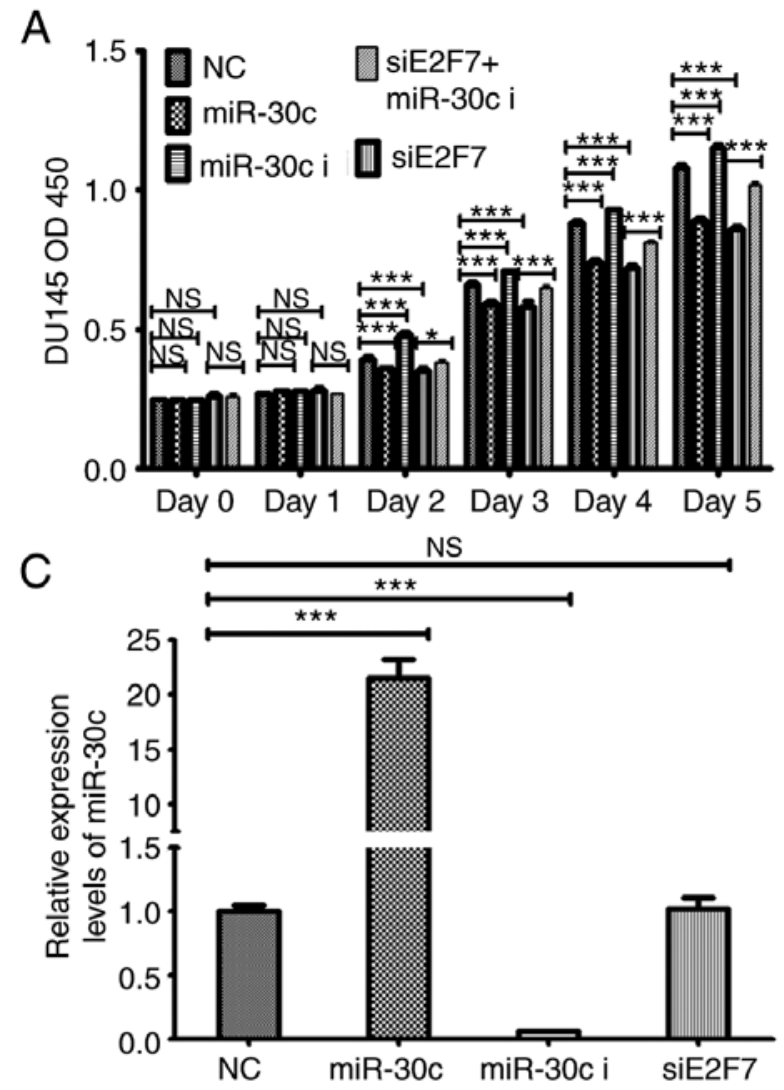

E

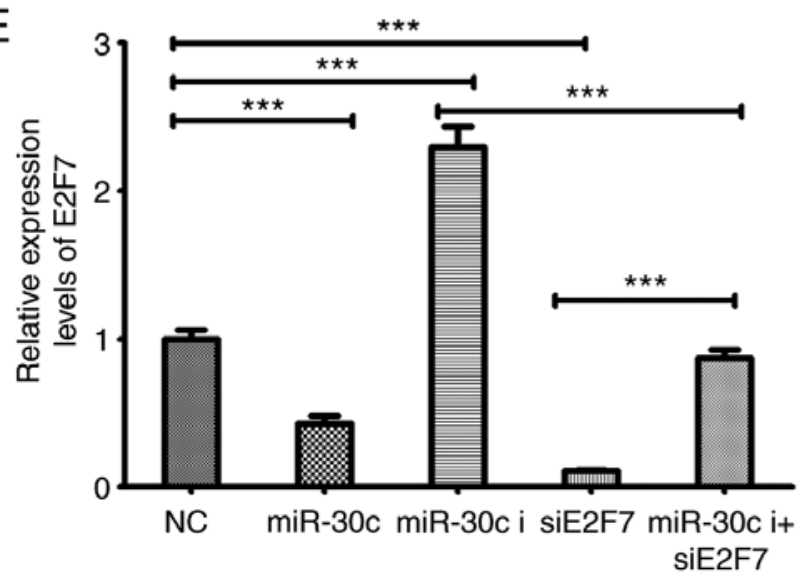

B
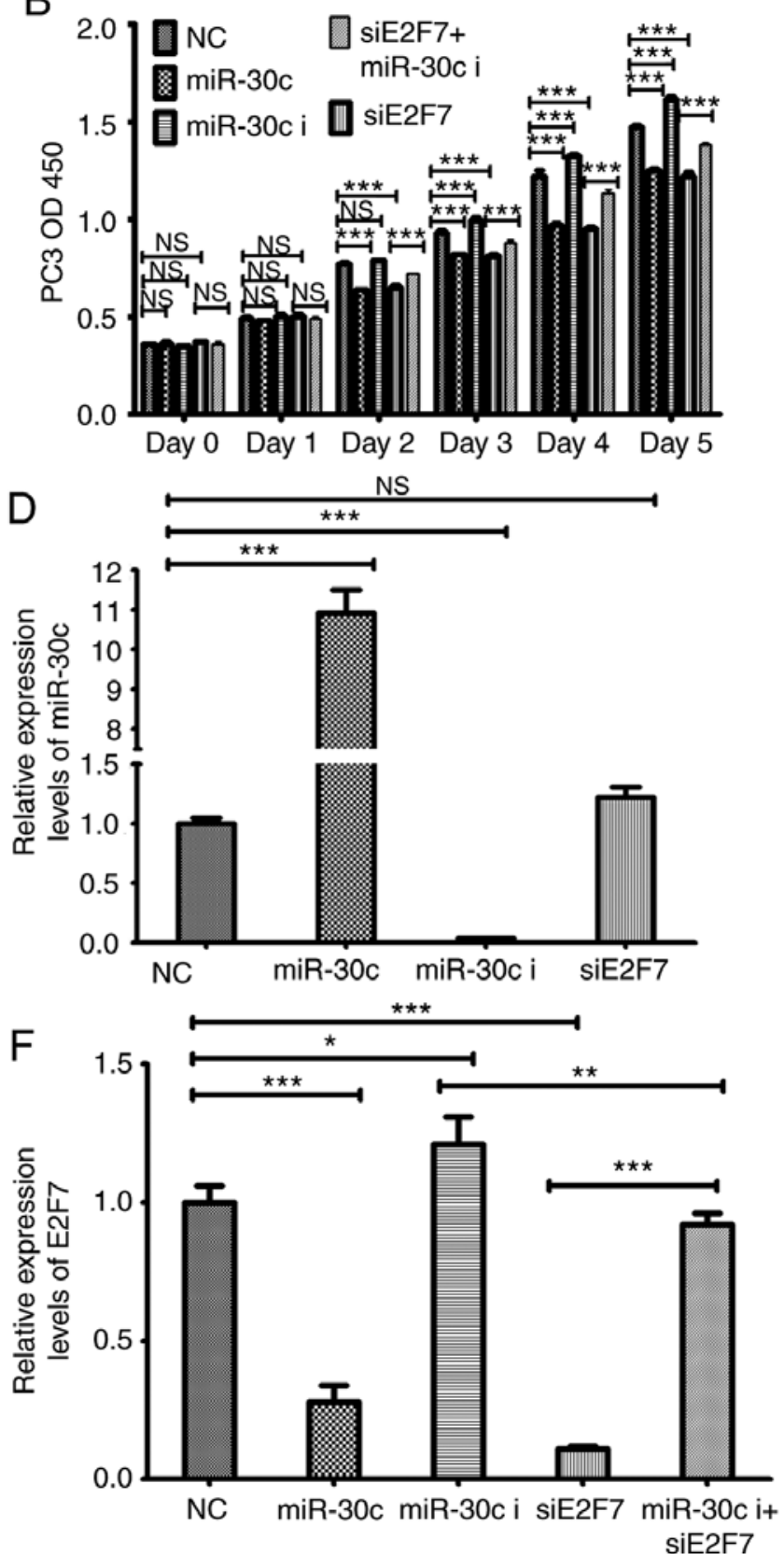

Figure 5. Investigation into the functional relationship between of E2F7 and miR-30c. Cell Counting kit-8 assay of (A) DU145 and (B) PC3 cells following transfection with miR-30c mimic, miR-30c inhibitor, siE2F7 or NC, or co-transfected with miR-30c inhibitor and siE2F7. miR-30c expression levels as measured in (C) DU145 and (D) PC3 cells following transfection with miR-30c mimic, miR-30c inhibitor, siE2F7 or NC or co-transfected with miR-30c inhibitor and siE2F7. The E2F7 expression levels in (E) DU145 and (F) PC3 cells following transfection with miR-30c mimic, miR-30c inhibitor, siE2F7 or NC, or co-transfected with miR-30c inhibitor and siE2F7. The values represent the mean $\pm \mathrm{SD}$ from three experimental repeats. ${ }^{*} \mathrm{P}<0.05$, ${ }^{* *} \mathrm{P}<0.01$ and ${ }^{* * * *} \mathrm{P}<0.0001$. OD, optical density; miR, microRNA; siRNA, small interfering RNA; miR-30c, miR-30c mimics; miR-30c i, miR-30c inhibitor; siE2F7, E2F7 siRNA; NC, negative control; NS, not significant.

vector encoding the 3'-UTR of either the wild-type or mut E2F7 and miR-30c mimics or miR-30c inhibitors. Wild-type and mut E2F7-3'-UTR containing the putative binding sites for miR-30c were cloned into the psiCHECK-2 vector downstream of the luciferase gene (Fig. S2). Co-transfection with the miR-30c mimic significantly reduced the luciferase activities of the E2F7 3'-UTR reporter vector, but not those of the E2F7-3'-UTR-mut vector (Fig. 2B and C). Sequencing data of the wild-type and mut E2F7-3'-UTR showed that miR-30c may directly regulate the expression levels of E2F7, where miR-30c may bind to the 3'-UTR of E2F7 mRNA and downregulate its expression (Fig. 2D).

E2F7 knockdown and upregulation of $\mathrm{miR}-30 \mathrm{c}$ reduces cell viability by increasing apoptosis whilst suppressing $S$ phase progression in PCa cells. To study the potential role of E2F7 and miR-30c in PCa cells, E2F7 siRNA, miR-30c mimics and miR-30c inhibitors were transiently transfected into DU145 and PC3 cell lines (Fig. S3). Cell counting Kit-8 (CCK-8) was used to calculate cell viability. Transfection with E2F7 siRNA and 
miR-30c mimics lead to significantly reduced PCa cell viability compared those transfected with negative controls $48 \mathrm{~h}$ after transfection and onwards (Fig. 3A and B). By contrast, transfection with the miR-30c inhibitors resulted in significantly increased cell viability compared with cells transfected with negative controls within the same timeframe (Fig. 3A and B). Further study showed that compared with cells transfected with the negative control, transfection with either the miR-30c mimics or E2F7 siRNA lead to significantly increased rates of apoptosis (Fig. 3C), significantly reduced the proportion of cells in the $S$ phase and increased the number of cells at the $G_{1}$ phase of the cell cycle (Fig. 4). Transfection with the miR-30c inhibitor resulted in significant reductions in apoptosis and significant increases in the percentage of cells in the $\mathrm{S}$ phase in both DU145 and PC3 cells, but did not significantly alter the percentage of cell PC3 cells in the $\mathrm{G}_{1}$ phase (Figs. 3 and 4).

E2F7 mediates the function of miR-30c. To study the relationship between miR-30c and E2F7, PCa cell lines were co-transfected with the miR-30 inhibitor and E2F7 siRNA. Co-transfection with the miR-30c inhibitor and E2F7 siRNA significantly increased cell viability compared with E2F7 siRNA transfection alone in both DU145 and PC3 cells from day 2 onwards (Fig. 5A and B). Transfection with E2F7 siRNA did not significantly change the expression levels of miR-30c in either PCa cell lines (Fig. 5C and D). By contrast, transfection with the miR-30c mimics lead to a significant downregulation in E2F7 expression, whilst transfection with the miR-30c inhibitor resulted in higher expression levels of E2F7. The effects mediated by the miR-30c inhibitor was significantly reversed by co-transfection with the E2F7 siRNA in both DU145 and PC3 cells (Fig. 5E and F).

In addition, EdU assay was subsequently performed, which found that transfection with the miR-30c inhibitor significantly increased EdU uptake in DU145 and PC3 cells (Fig. 6A and B), which was reversed by co-transfection with E2F7 siRNA (Fig. 6A and B). Additionally, western blotting experiments also showed that overexpression and inhibition of miR-30c expression led to significant downregulation and upregulation of E2F7 expression in both PCa cell lines (Fig. 6C-F), respectively. These findings suggested that miR-30c overexpression inhibited PCa cell proliferation by potentially inhibiting E2F7 expression.

miR-30c/E2F7/p21 may serve as a pathway to promote the development of $\mathrm{PCa}$. E2F7 has been previously shown to negatively regulate the expression of the universal cell cycle inhibitor p21 $(9,10)$. To investigate the mechanism by which miR-30c/E2F7 promotes the development of $\mathrm{PCa}$, p21 expression in $\mathrm{PCa}$ cell lines following transfection with E2F7 siRNA, miR-30c mimics, miR-30c inhibitor or NC was then investigated further. In both cell lines, compared with cells transfected with $\mathrm{NC}$, p21 expression was revealed to be significantly increased on both mRNA (Fig. 7A and B) and protein (Fig. 7C and D) levels following transfection with E2F7 siRNA or miR-30c mimics, whilst transfection with the miR-30c inhibitor resulted in significant downregulation of p21. Co-transfection of both cell lines with the miR-30c inhibitor and E2F7 siRNA led to significantly increased upregulation in $\mathrm{p} 21$ expression compared with cells transfected with the miR-30c inhibitor alone (Fig. 7C-F). The association between E2F7 and p21 expression was analyzed further by immunohistochemistry, which showed that the levels of E2F7 expression associated negatively with p21 expression, especially in identical locations within the same sample of the tissue array (Fig. S4). These observations suggest that p21 expression may be negatively regulated by E2F7. In addition, it was found that E2F7 knockdown led to a higher magnitude of upregulation in $\mathrm{p} 21$ expression compared with that induced by the introduction of miR-30c mimics in both cell lines tested (Fig. 7). Therefore, these findings suggest that the miR-30c/E2F7/p21 pathway promotes the development of PCa (Fig. 8).

\section{Discussion}

The E2F family of transcription factors serve important roles in the regulation of cell cycle progression (29). E2F7 and E2F8 are considered to be atypical members of the E2F family due to reported suppressive roles on the transcription of genes associated with DNA replication, resulting in $\mathrm{S}$ phase cell cycle arrest and inhibition of tumorigenesis $(30,31)$. Interestingly, E2F7/8 double-knockout mice have been previously found to exhibit vascular defects and extensive apoptosis (32). In addition, it has been found that E2F7, which is reported to be involved in the DNA damage $(33,34)$. response and control of E2F target genes associated with cell cycle progression as well as the proliferation and apoptosis of keratinocytes (35), has been revealed to promote tumorigenesis in some malignant tumors $(11,36)$.

The role of E2F7/8 in the development of tumors remain unclear. Ma et al (9) reported that high levels of E2F7 expression was correlated with shorter median overall survival and progress-free survival in hepatocellular carcinoma patients. Despite their classification as transcriptional repressors, Weijts et al (37) demonstrated that E2F7/8 is essential for the opportune development of blood vessels. Similarly, the high expression of E2F7 was found to be correlated with higher risks of relapse and poor prognosis in patients with breast cancer that were treated with tamoxifen (38).

In the present study, it was found that the staining scores of E2F7 in PCa tissues was higher compared with those of adjacent normal tissues. Transfections of PCa cells with E2F7 siRNA resulted in significantly reduced cell viability, increased proportion of cells in the $G_{1}$ phase and higher apoptotic rates. Strategies combining cell cycle inhibitors in castration-resistant prostate cancer (CRPC) have been considered to have beneficial effects with CDK4/6 and Weel inhibitors (39). S phase inhibitors, including M-6620 and prexasertib, $\mathrm{G}_{1}$ phase inhibitors including AZD-5363 (39), palbociclib (39), and ipatasertib (40), $\mathrm{G}_{2}$ phase inhibitors such as adavosertib (39) and $M$ phase inhibitors such as alisertib (41) are all undergoing clinical trials and may prove promising in targeted therapies for CRPC in the future. Linking cell cycle to the inhibition of prostate cancer pathophysiology, Kang et al (42) reported that TJ001 promoted $\mathrm{G}_{1} / \mathrm{S}$ cell cycle arrest by upregulating p21Cip1/WAF1 expression whilst downregulating cyclin E and cyclin D1 expression. The mechanism underlying the E2F7-mediated regulation of tumorigenesis could be through the inhibition of gene 

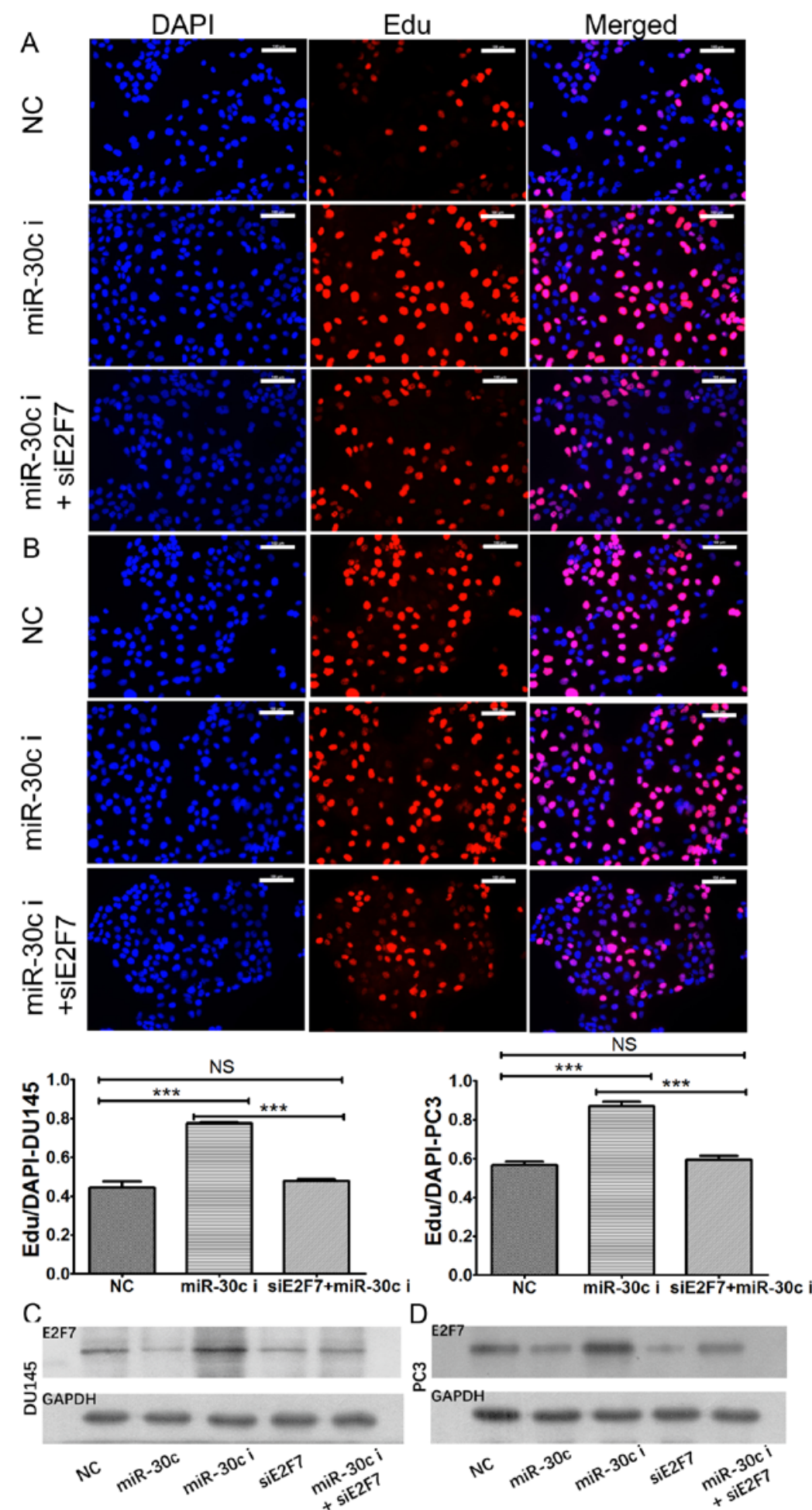

$\mathrm{E}$

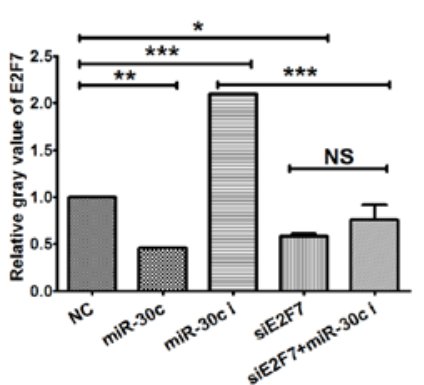

$\mathrm{F}$

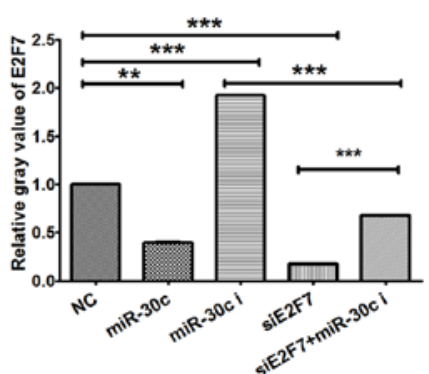

Figure 6. Effect of E2F7 on miR-30c function. According to the results from EdU assay, miR-30c knockdown significantly promoted EdU uptake in (A) DU145 and (B) PC3 cell lines, which was reversed by co-transfection with E2F7 siRNA. Western blotting experiments showed that upregulation and downregulation of miR-30c resulted in the downregulation and upregulation of E2F7 expression in (C) DU145 and (D) PC3 cell lines, respectively. The values represent the mean \pm SD from three experimental repeats of (E) DU145 and (F) PC3 cell lines. ${ }^{*} \mathrm{P}<0.05,{ }^{* *} \mathrm{P}<0.01$ and ${ }^{* * * *} \mathrm{P}<0.0001$. Scale bar, $100 \mu \mathrm{m}$. EdU, 5-Ethynyl-2'deoxyuridine; miR, microRNA; miR-30c, miR-30c mimics; miR-30c i, miR-30c inhibitor; siE2F7, E2F7 siRNA. 

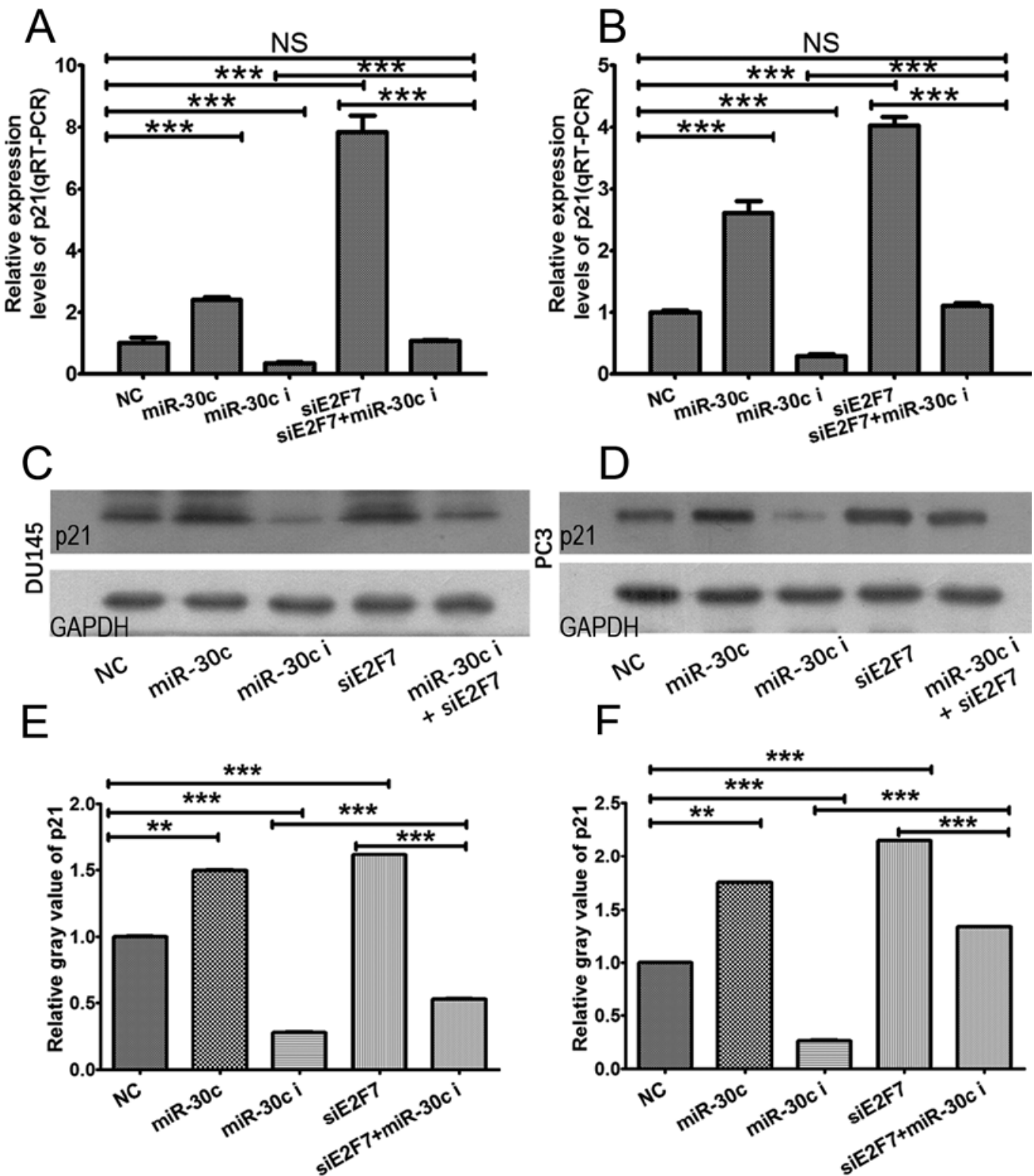

Figure 7. Effect of miR-30c and E2F7 on p21 expression in PCa cells. p21 mRNA expression in (A) DU145 and (B) PC3 cells following transfection with miR-30c mimics, miR-30c inhibitors, NC or siE2F7 or co-transfection with siE2F7 and miR-30c inhibitors. p21 protein expression in (C) DU145 and (D) PC 3 cells following transfection with miR-30c mimics, miR-30c inhibitors, $\mathrm{NC}$ or siE2F7 or co-transfection with siE2F7 and miR-30c inhibitors. The values represent the mean \pm SD from three experimental repeats of (E) DU145 and (F) PC3 cell lines. ${ }^{* * *} \mathrm{P}<0.01$ and ${ }^{* * * *} \mathrm{P}<0.0001$. miR, microRNA; NC, negative control; miR-30c, miR-30c mimics; miR-30c I, miR-30c inhibitor; siE2F7, E2F7 siRNA.

expression associated with the maintenance of genomic stability (43).

The present study showed E2F7 to be one of the targets of miR-30c, which was examined using Dual-luciferase reporter assay. Previous studies have demonstrated that miR-30c involvement is critical for the development of a variety of human cancers. It has also been found that miR-30c functioned as a tumor suppressor (44), where it inhibited cancer metastasis (36) by directly targeting genes associated with metastasis $(37,38)$. Huang et al (21) reported that miR-30c reduced PCa survival by targeting the ASF/SF2 splicing factor oncoprotein whilst Ling et al (46) found that the B-cell lymphoma 9 protein, a coactivator for $\mathrm{Wnt} / \beta$-catenin transcription, was targeted by miR-30c, which was associated with PCa progression. In the present study, it was demonstrated that transfection with the
miR-30c mimics led to increased apoptotic rates compared with the corresponding negative control, consistent with a previous conclusion (45). In addition, previous data suggested that downregulation of the tumor suppressor miR-30c was a frequent pathological event in PCa (46), where it was revealed that miR-30c appears to be a tumor suppressor gene in DU145 cells (21). In the present study, luciferase reporter assays were performed to verify if E2F7 is a direct target of miR-30c using DU145 and PC3 cell lines. In addition, the androgen-dependent $\mathrm{VCaP}$ cell line, was used to examine the miR-30c effect on E2F7 and p21 expression by western blotting method, and the results were consistent with that of the DU145 and PC3 cell lines (data not shown).

In terms of cell cycle progression, it would be ideal to perform these types of experiments in a synchronized manner. 


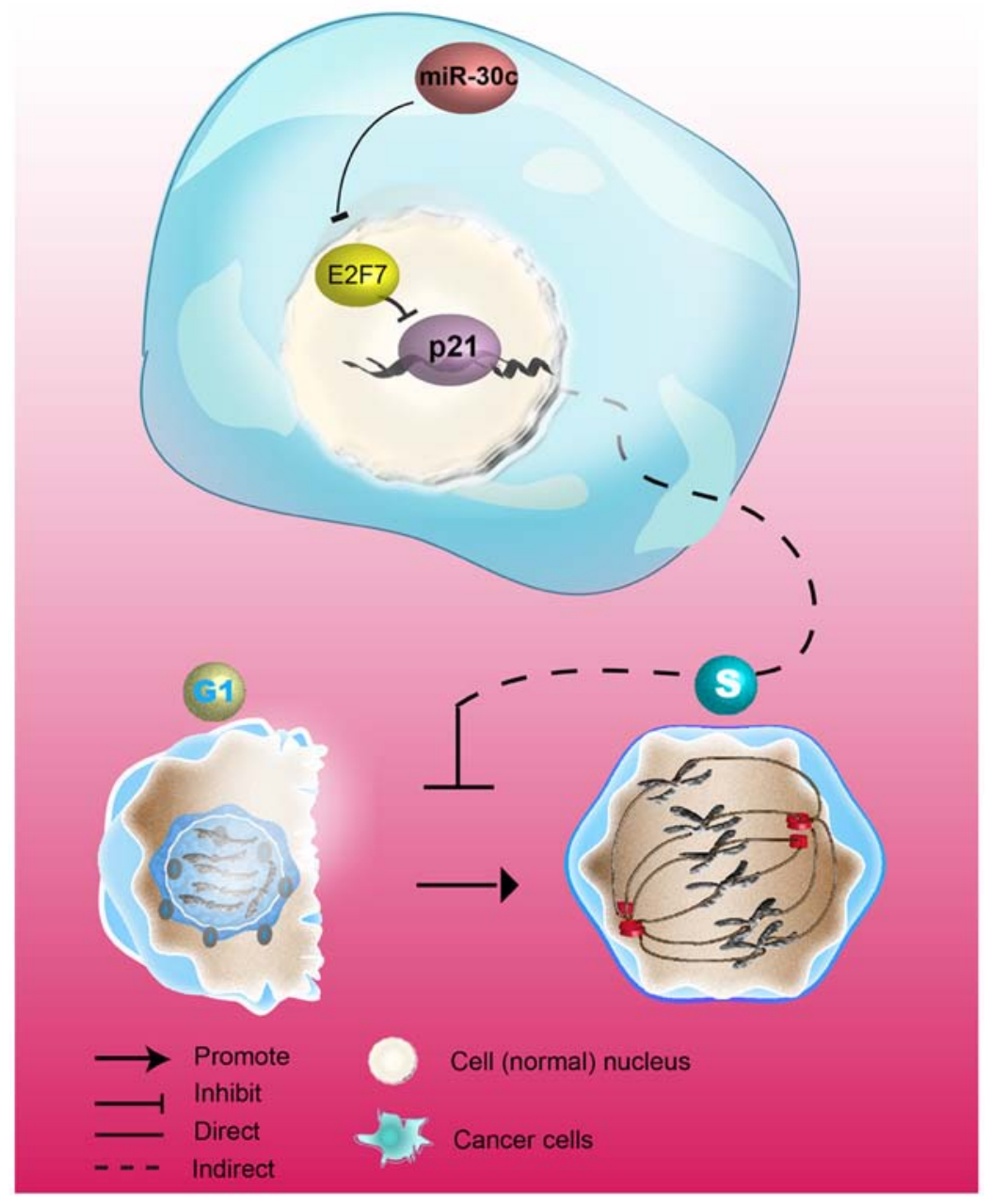

Figure 8. Schematic diagram of the miR-30c/E2F7/p21 pathway. The hypothesis of the mechanism underlying prostate cancer tumorigenesis in the present study is the negative regulation of $\mathrm{p} 21$ by E2F7, which is in turn negatively regulated by miR-30c.

In the present study, it was confirmed that the inhibition of proliferation mediated by miR-30c in PCa cell lines was by targeting E2F7 expression; specifically, co-transfection of the miR-30 inhibitor with E2F7 siRNA resulted in lower cell viability compared with E2F7 siRNA transfection alone. E2F7 siRNA transfection did not significantly change the expression levels of miR-30c in PCa cell lines. However, transfection with the miR-30c mimic led to the significant reductions in E2F7 expression, whilst transfection with the miR-30c inhibitor resulted in increased E2F7 expression which was reversed by co-transfection with E2F7 siRNA in both DU145 and PC3 cells.

E2F7 has been previously demonstrated to negatively regulate p21 (9), a universal cell-cycle inhibitor (10) which can be controlled by p53 and p53-independent pathways (17). In the present study, it was found that $\mathrm{p} 21$ expression was significantly increased by transfection with either E2F7 siRNA or miR-30c mimics but significantly reduced by miR-30c inhibitor transfection compared with the negative control in PCa cells. In addition, E2F7 knockdown appeared to be more effective in upregulating p21 expression compared with miR-30c mimics in $\mathrm{PCa}$ cells, suggesting that $\mathrm{p} 21$ expression might be negatively regulated by E2F7 in PCa cells.
In conclusion, the present study demonstrated that E2F7 may serve a proliferative role in PCa cells by inhibiting p21. In addition, E2F7 was found to be negatively regulated by miR-30c, suggesting that miR-30c/E2F7/p21 may be a viable therapeutic target pathway for interventions against $\mathrm{PCa}$.

\section{Acknowledgements}

The authors would like to thank Professor Xin Gao, Department of Urology, The Third Affiliated Hospital, Sun Yat-Sen University (Guangzhou, China) for his generous donation of prostate cell lines DU145, PC3 and the normal prostate cell line RWPE1. The abstract of this manuscript was presented online (abstract no. e16568) at the 2019 American Society of Clinical Oncology meeting (Chicago, USA) in Journal of Clinical Oncology 37 (Suppl 15): 2019.

\section{Funding}

The present study was supported by the National Natural Science Foundation of China (grant nos. 81572849, 81772631 and 81301763) and Sanming Project of Medicine in Shenzhen (grant no. SZSM201612023) 


\section{Availability of data and materials}

The datasets used and/or analyzed during the current study are available from the corresponding author on reasonable request.

\section{Authors' contributions}

YW initiated the project, designed and performed the experiments, interpreted the data and wrote the manuscript. XJP performed the IHC experiment and data analysis, PX performed cell cycle data analysis, ZBT, ZWZ and ZYJ performed the reverse transcription-quantitative PCR and apoptosis data analysis. GPZ and ZD interpreted the data and edited figures. All authors read and approved the final version of the manuscript.

\section{Ethics approval and consent to participate}

The procedures used in the present study were approved (approval no. YB M-05-01 V.2) by the Ethics Committee of the Shanghai Outdo Biotech Company, a member of the National Human Genetic Resources Sharing Service Platform (Shanghai, China) and were performed in accordance with the ethical standards of The Institutional and National Research Committee and with The Declaration of Helsinki. Written informed consent was acquired from all patients.

\section{Patient consent for publication}

Not applicable.

\section{Competing interests}

The authors declare that they have no competing interests.

\section{References}

1. Siegel RL, Miller KD and Jemal A: Cancer statistics, 2018. CA Cancer J Clin 60: 277-300, 2018.

2. Nelson WG, De Marzo AM and Isaacs WB: Prostate cancer. N Engl J Med 349: 366-681, 2003.

3. Nevins JR: The Rb/E2F pathway and cancer. Human Mol Genet 10: 699-703, 2001

4. Dyson N: The regulation of E2F by pRB-family proteins. Genes Dev 12: 2245-2262, 1998.

5. Thwaites MJ, Cecchini MJ and Dick FA: Analyzing RB and E2F during the $\mathrm{G}_{1}-\mathrm{S}$ transition. Methods Mol Biol 1170: 449-461, 2014.

6. Subtil-Rodríguez A, Vázquez-Chávez E, Ceballos-Chávez M, Rodríguez-Paredes M, Martín-Subero JI, Esteller M and Reyes JC: The chromatin remodeller CHD8 is required for E2F-dependent transcription activation of S-phase genes. Nucleic Acids Res 42: 2185-2196, 2014.

7. De AB, Maiti B, Jakoi L, Timmers C, Buerki R and Leone G: Identification and characterization of E2F7, a novel mammalian E2F family member capable of blocking cellular proliferation. J Biol Chem 278: 42041-42049, 2003.

8. Zong S, Liu X, Zhou N and Yue Y: E2F7, EREG, miR-451a and miR-106b-5p are associated with the cervical cancer development. Arch Gynecol Obstet 299: 1089-1098, 2019.

9. Ma YS, Lv ZW, Yu F, Chang ZY, Cong XL, Zhong XM, Lu GX, Zhu J and Fu D: MicroRNA-302a/d inhibits the self-renewal capability and cell cycle entry of liver cancer stem cells by targeting the E2F7/AKT axis. J Exp Clin Cancer Res 37: 252, 2018.
10. Salvatori B, Iosue I, Mangiavacchi A, Loddo G, Padula F, Chiaretti S, Peragine N, Bozzoni I, Fazi F and Fatica A: The microRNA-26a target E2F7 sustains cell proliferation and inhibits monocytic differentiation of acute myeloid leukemia cells. Cell Death \& Disease 3: e413, 2012.

11. Jian L, Xiang L, Meng W, Xiao G, Yang G, Wang H, Li Y, Sun X, Qin S, Du N, et al: A miR-26a/E2F7 feedback loop contributes to tamoxifen resistance in ER-positive breast cancer. Int J Oncol 53: 1601-1612, 2018

12. Endo-Munoz L, Dahler A, Teakle N, Rickwood D, Hazar-Rethinam M, Abdul-Jabbar I, Sommerville S, Dickinson I, Kaur P, Paquet-Fifield S and Saunders N: E2F7 can regulate proliferation, differentiation, and apoptotic responses in human keratinocytes: Implications for cutaneous squamous cell carcinoma formation. Cancer Res 69: 1800-1808, 2009.

13. Quan L, Qiu XM, Li QH, Wang XY, Li L, Xu M, Dong M and Xiao YB: MicroRNA-424 may function as a tumor suppressor in endometrial carcinoma cells by targeting E2F7. Oncology Rep 33: 2354-2360, 2015.

14. Ye YY, Mei JW, Xiang SS, Li HF, Ma Q, Song XL, Wang Z, Zhang YC, Liu YC, Jin YP, et al: MicroRNA-30a-5p inhibits gallbladder cancer cell proliferation, migration and metastasis by targeting E2F7. Cell Death Dis 9: 410, 2018.

15. Karimian A, Ahmadi Y and Yousefi B: Multiple functions of p21 in cell cycle, apoptosis and transcriptional regulation after DNA damage. DNA Repair (Amst.) 42: 63-71, 2016.

16. Jun L, Gad G, Miska EA, Alvarez-Saavedra E, Lamb J, Peck D, Sweet-Cordero A, Ebert BL, Mak RH, Ferrando AA, et al: MicroRNA expression profiles classify human cancers. Nature 435: 834-838, 2005.

17. Behmansmant I, Rehwinkel J, Doerks T, Stark A, Bork P and Izaurralde E: mRNA degradation by miRNAs and GW182 requires both CCR4:NOT deadenylase and DCP1:DCP2 decapping complexes. Genes Dev 20: 1885-1898, 2006.

18. Lytle JR, Yario TA and Steitz JA: Target mRNAs are repressed as efficiently by microRNA-binding sites in the 5' UTR as in the 3' UTR. Proc Natl Acad Sci USA 104: 9667-9672, 2007.

19. Cao JM, Li GZ, Han M, Xu HL and Huang KM: MiR-30c-5p suppresses migration, invasion and epithelial to mesenchymal transition of gastric cancer via targeting MTA1. Biomed Pharmacother 93: 554-560, 2017.

20. Huang J, Yao X, Zhang J, Dong B, Chen Q, Xue W, Liu D and Huang Y: Hypoxia-induced downregulation of miR-30c promotes epithelial-mesenchymal transition in human renal cell carcinoma. Cancer Sci 104: 1609-1617, 2013.

21. Huang YQ, Ling XH, Yuan RQ, Chen ZY, Yang SB, Huang HX, Zhong WD and Qiu SP: miR-30c suppresses prostate cancer survival by targeting the ASF/SF2 splicing factor oncoprotein. Mol Med Rep 16: 2431-2438, 2017.

22. Tanic M, Yanowsky K, Rodriguez-Antona C, Andrés R, Márquez-Rodas I, Osorio A, Benitez J and Martinez-Delgado B: Deregulated miRNAs in hereditary breast cancer revealed a role for miR-30c in regulating KRAS oncogene. PLoS One 7: e38847, 2012.

23. GJ L: ETHICS. The Pelople's publishing house, 1989.

24. Livak KJ and Schmittgen TD: Analysis of relative gene expression data using real-time quantitative PCR and the 2(-Delta Delta C(T) method. Methods 25: 402-408, 2001.

25. Kurien BT and Scofield RH: Western blotting. Methods 38: 283-293, 2006.

26. Madamanchi NR and Runge MS: Western blotting. Methods Mol Med 51: 245-256, 2001

27. Miyake M, Goodison S, Lawton A, Gomes-Giacoia E and Rosser CJ: Angiogenin promotes tumoral growth and angiogenesis by regulating matrix metallopeptidase- 2 expression via the ERK1/2 pathway. Oncogene 34: 890-901, 2015.

28. Giacoia EG, Miyake M, Lawton A, Goodison S and Rosser CJ: PAI-1 leads to $\mathrm{G}_{1}$-phase cell-cycle progression through cyclin D3/cdk4/6 upregulation. Mol Cancer Res 12: 322-334, 2014.

29. La Thangue NB: DRTF1/E2F: An expanding family of heterodimeric transcription factors implicated in cell-cycle control. Trends Biochem Sci 19: 108-114, 1994.

30. Zhao LJ, Subramanian T, Vijayalingam S and Chinnadurai G: $\mathrm{CtBP} 2$ proteome: Role of $\mathrm{CtBP}$ in $\mathrm{E} 2 \mathrm{~F} 7$-mediated repression and cell proliferation. Genes Cancer 5: 31-40, 2014.

31. Weijts BGMW, Westendorp B, Hien BT, Martínez-López LM Zijp M, Thurlings I, Thomas RE, Schulte-Merker S, Bakker WJ and de Bruin A: Atypical E2Fs inhibit tumor angiogenesis. Oncogene 37: 271-276, 2018. 
32. Li J, Ran C, Li E, Gordon F, Comstock G, Siddiqui H, Cleghorn W, Chen HZ, Kornacker K, Liu CG, et al: Synergistic function of E2F7 and E2F8 is essential for cell survival and embryonic development. Dev Cell 14: 62-75, 2008.

33. Zalmas LP, Zhao X, Graham AL, Fisher R, Reilly C, Coutts AS and La Thangue NB: DNA-damage response control of E2F7 and E2F8. EMBO Rep 9: 252-259, 2008.

34. Zalmas LP, Coutts A, Helleday T and La Thangue NB: E2F-7 couples DNA damage-dependent transcription with the DNA repair process. Cell Cycle 12: 3037-3051, 2013

35. Carvajal LA, Hamard PJ, Tonnessen C and Manfredi JJ: E2F7, a novel target, is up-regulated by p53 and mediates DNA damage-dependent transcriptional repression. Genes Dev 26: $1533-1545,2012$.

36. Yin WW, Wang B, Ding M, Huo Y, Hu H, Cai R, Zhou T, Gao Z, Wang Z and Chen D: Elevated E2F7 expression predicts poor prognosis in human patients with gliomas. J Clin Neurosci 33: 187-193, 2016.

37. Weijts BG, Bakker WJ, Cornelissen PW, Liang $\mathrm{KH}$, Schaftenaar FH, Westendorp B, de Wolf CA, Paciejewska M, Scheele CL, Kent L, et al: E2F7 and E2F8 promote angiogenesis through transcriptional activation of VEGFA in cooperation with HIF1. EMBO J 31: 3871-3884, 2012.

38. Chu J, Zhu Y, Liu Y, Sun L, Lv X, Wu Y, Hu P, Su F, Gong C, Song E, et al: E2F7 overexpression leads to tamoxifen resistance in breast cancer cells by competing with E2F1 at miR-15a/16 promoter. Oncotarget 6: 31944-31957, 2015.

39. Batra A and Winquist E: Emerging cell cycle inhibitors for treating metastatic castration-resistant prostate cancer. Expert Opin Emerg Drugs 23: 271-282, 2018.

40. Zhu R, Poland B, Wada R, Liu Q, Musib L, Maslyar D, Cho E, $\mathrm{Yu}$ W, Ma H, Jin JY and Budha N: Exposure-response-based product profile-driven clinical utility index for ipatasertib dose selection in prostate cancer. CPT Pharmacometrics Syst Pharmacol 8: 240-248, 2019.
41. Beltran H, Danila D, Montgomery B, Szmulewitz R, Vaishampayan U, Armstrong A, Stein M, Hoimes C, Pinski J, Scher H, et al: A phase 2 study of the aurora kinase A inhibitor alisertib for patients with neuroendocrine prostate cancer (NEPC). Ann Oncol 27 (Suppl 6): V1565, 2016.

42. Kang SY, Kim HI, Hong SH, Ku JM, Lee K, Kim MS, Choi YJ, Cheon C, Ko Y, Huang CW, et al: Abstract 300: Taeumjowi-tang (TJ001) induces $\mathrm{G}_{2} / \mathbf{M}$ cell cycle arrest but not apoptosis in p53-mutant prostate cancer via up-regulation of p21 WAF/CIP1. Cancer Res 77 (Suppl 13): 300, 2017.

43. Mitxelena J, Apraiz A, Vallejo-Rodríguez J, García-Santisteban I, Fullaondo A, Alvarez-Fernández $\mathrm{M}$, Malumbres $\mathrm{M}$ and Zubiaga AM: An E2F7-dependent transcriptional program modulates DNA damage repair and genomic stability. Nucleic Acids Res 46: 4546-4559, 2019.

44. Bockhorn J, Yee K, Chang YF, Prat A, Huo D, Nwachukwu C, Dalton R, Huang S, Swanson KE, Perou CM, et al: MicroRNA-30c targets cytoskeleton genes involved in breast cancer cell invasion. Breast Cancer Res Treat 137: 373-382, 2013.

45. Liu X, Li M, Peng Y, Hu X, Xu J, Zhu S, Yu Z and Han S: miR-30c regulates proliferation, apoptosis and differentiation via the Shh signaling pathway in P19 cells. Exp Mol Med 48: e248, 2016

46. Ling XH, Han ZD, Xia D, He HC, Jiang FN, Lin ZY, Fu X, Deng YH, Dai QS, Cai C, et al: MicroRNA-30c serves as an independent biochemical recurrence predictor and potential tumor suppressor for prostate cancer. Mol Biol Rep 41: 2779-2788, 2014

This work is licensed under a Creative Commons

Attribution-NonCommercial-NoDerivatives 4.0 International (CC BY-NC-ND 4.0) License. 